\title{
A Review Study on Legs Lameness and Weaknesses Assessment Methods in Commercial Broiler Farming in Pakistan
}

\author{
Adnan Yousaf ${ }^{1 *}$, Sambreena Tunio ${ }^{1}$, Ghulam Mohy-ud-din² , Amanullah Kakar², Faiza Habib ${ }^{2}$, Ali \\ Gul Soomro ${ }^{1}$, Wafa Akram³ ${ }^{3}$, Saba Naazir ${ }^{1}$, Mariyam Ismail ${ }^{1}$, Tehmina Naazir ${ }^{4}$ and Nida Naazir ${ }^{1}$ \\ ${ }^{1}$ Sindh Agriculture University Tandojam, Pakistan
}

${ }^{2}$ Department of Livestock and Dairy Development Quetta, Pakistan

${ }^{3}$ University of Veterinary and Animal Sciences Lahore, Pakistan

${ }^{4}$ Department of Livestock and Dairy Development Punjab, Pakistan

*Corresponding author: Adnan Yousaf, Sindh Agriculture University Tandojam, Pakistan

\begin{tabular}{l} 
ARTICLE INFO \\
\hline Received: 㓞 November 23, 2021 \\
Published: 㓞 December 01, 2021 \\
\hline Citation: Adnan Yousaf, Sambreen Tunio, \\
Ghulam Mohy-ud-din, Amanullah Kakar, \\
Faiza Habib, et al., A Review Study on Legs \\
Lameness and Weaknesses Assessment \\
Methods in Commercial Broiler Farming \\
in Pakistan. Biomed J Sci \& Tech Res \\
40(2)-2021. BJSTR. MS.ID.006433.
\end{tabular}

Keywords: Precision Livestock Farming; Commercial Poultry; Lameness; Chicken; Technology

\begin{abstract}
First, a brief history of chickens was discussed, followed by an investigation of the term "leg weakness" and what it implies in the broiler industry. Leg weakness is a broad phrase that refers to infective and non-infectious characteristics found in contemporary, fast-growing broilers. Commercially raised modern broilers are prone to foot issues such as lameness, footpad dermatitis, and hock burn. Lameness is a broad word that refers to a variety of injuries in commercial poultry caused by infectious and non-infectious sources. In the poultry business (Broiler, Breeders and Layers), lameness is a major issue. In 2010 , the expense of lameness was estimated to be between $\$ 80$ million and \$120 million in the United States. However, it has been established in the literature that lameness is closely linked to weight, growth rate, and activity. In 80 years, the time it takes for a chick to attain a live weight of $1500 \mathrm{~g}$ was decreased from 120 days to 30 days. Broiler chicks have had serious difficulties as a result of their rapid growth. Animals with serious issues, for example, have poorer feed efficiency and growth. The value of these animals' carcasses has likewise been reduced. In addition to the welfare issues that have arisen as a result of leg difficulties, the producers have also suffered financial losses. As a result, the initial goal of this study is to evaluate broiler leg deficiencies and offer readers with a brief explanation of the elements that influence this condition. The second goal of this research is to examine commercial poultry lameness and lameness evaluation techniques. Furthermore, the benefits and drawbacks of various approaches are explored. Brief findings and a reference list may be found at the end of this review.
\end{abstract}

\section{Introduction}

The poultry business has expanded dramatically over the last fifty years, with more than 35 billion broiler birds produced each year [1]. Due to the economic benefits of increasing body weight, the need for enhanced growth rate and output has resulted in differential growth of body components, such as rapid muscular growth [2]. This expansion, however, is not accompanied by skeletal development. Lame broilers have trouble walking and, as a result, they can't go to the feeder or drinker when they are hungry or thirsty [2]. Their quality of life is being harmed by their laziness. The presence of lameness in birds is significantly linked to their weight and fast development [3]. Furthermore, the broilers may experience discomfort as a result of mobility issues. It can reduce 
bird's activity and cause a variety of issues, such as hock burns and chest dirtiness [4]. Broiler chicks are protected against frailty by a rapid development rate coupled by appropriate feeding, good management, ideal lighting and temperature, and a disease-free environment [5]. Leg diseases are caused by the lack of any of these components in combination with inherent weight-bearing features [3]. Infectious, developmental, metabolic, and degenerative diseases can all cause leg weakness. Leg ailment is associated with a higher rate of morbidity than mortality [3]. The handicapped bird, on the other hand, suffers from discomfort, is unable to obtain food and water, and eventually dies from inanition [6]. As a result, the initial goal of this study is to evaluate broiler leg deficiencies and offer readers with a brief explanation of the elements that influence this condition [7]. Nutritional deficiencies, mechanically produced injuries, toxins, genetic abnormalities, infections infectious illnesses, sex, weight and development rate, age, feed conversion efficiency, handling, and mobility are all variables that contribute to leg weakness [8]. The second goal of this research is to examine broiler lameness and lameness evaluation techniques.

\section{Leg Problems}

Broiler nutritional and physical density rose as a result of the food modifications. Higher nutrient intakes, as well as a combination of these two variables, have resulted in a significant increase in broiler growth rates [9]. To use this genetic potential for growth, the time until the chick reaches a live weight of $1500 \mathrm{~g}$ was lowered from 16 weeks to 4 weeks. Good highly concentrated feed in pellet form and intensive lighting cycles are necessary [10]. A high body weight has also been chosen for the creation of more breast muscles, in addition to a selection for quick growth to rap to accomplish. This causes the chicks' conformation to alter, which can lead to bone deformities [11]. In addition to the welfare issues caused by leg difficulties, the producer will suffer a financial loss. Animals with serious issues have a poorer feed efficiency and develop at a slower rate. These animals' carcass quality will deteriorate as well [12].

\section{Occurrence}

The majority of broiler lameness is caused by skeletal anomalies, although this is difficult to explain. Increases in the mortality rate, "the cull," the percentage of rejected chicks, and "downgrades from trimming" [13] may result from the costs and losses incurred as a result of bone abnormalities. Broiler losses due to skeletal anomalies are considerable (Garner et al., 2002). At some stables, up to $90 \%$ of the birds in slaughter age show some degree of lameness [14], and roughly $30 \%$ of the birds are just too badly handicapped [15].

\section{Behavioral Changes}

A roaster's day is spent for the most part. The hens appear to sleep around a quarter of the time and do nothing more than half of the time. A healthy chicken spends $76 \%$ of its time laying down. This proportion rises with age, and it appears to be substantially greater with a higher level of lameness (up to $86 \%$ ).

\section{Defects and their Types}

Broiler lameness is caused by a variety of factors, including abnormalities and illness. Heavy, disease-free birds wander about her as though she's in pain and want to stay. This might imply that the discomfort is caused by body weight and strain on the bones and tissues [16].

\section{Abnormalities of the Bones}

Nutritional deficiencies, mechanically produced injuries, toxins, and genetic flaws are all possible causes of bone abnormalities [17]. All of these features are more important in fast-growing chicken breeds. They require it for their quick expansion. Because their bones are not fully formed, they are more prone to damage as they consume more and more specialized nutrients. As a result, bone anomalies are prevalent in commercial broiler production.

\section{Valgus-Varus}

A "knock-kneed" look is caused by valgus deviation. When the tars metatarsus is lined up with the tibiotarsus, the tars metatarsus deviates laterally. It's the most frequent type of long bone deformity, and it's also the most dangerous [18]. This aberration gives the impression of being 'bowlegged.' The tars metatarsus differs in that it now wonders whether she will be positioned on a line with the tibiotarsus. This aberration is less frequent, but it can cause serious walking problems [19].

\section{Dyschondroplasia of the Tibia (Td)}

TD appears to be a dissociation of growth plate chondrocyte proliferation and leg extension during endochondral calcification [20].

\section{Rickets}

This is most likely the most well-known bone disease in poultry. When bone mineralization is decreased, this occurs. A lack of calcium and phosphorus, or an imbalance between the two, is the most prevalent cause [21]. 'Rickets' can affect both rapid and slowgrowing chicks, although they are exacerbated by the increased requirement for nutrition during growth.

\section{Necrosis of the Femoral Head}

The reasons of this condition are unknown, but it has the potential to impact the entire house. The incapacity of the broilers to stand up is the most obvious sign [22]. It is the end of the femur when an autopsy is performed on the birds. Although broilers can respond to vitamin D3 in drinking water, this approach does not always effective [23]. 


\section{Chondrodystrophie}

Shorter bones with various anomalies can occur in poultry lacking in water-soluble vitamins. If the deficit is severe enough, the supporting gastronomies tendon might slide cartilage [24].

\section{Dermatitis due to Contact}

Feet burns, also known as contact dermatitis, have been more common in broilers during the last few decades. Contact dermatitis is thought to be induced by the ammonium chemical's action on the urea in the litter. There is also evidence that the occurrence and severity of contact dermatitis are related to the litter and air quality, and hence to welfare factors other than pain [25]. Because of the amount of time spent sitting and the poor quality of the litter, contact dermatitis is evident. The amount of time the chicks spend sitting and reclining rises with age, from $75 \%$ in the first week to $90 \%$ at five weeks [26]. Footpad dermatitis is a form of contact dermatitis that causes sores on the soles of chickens' feet. Swelling and necrotizing tissue can develop or be seen in more severe instances [27]. This might pose a food safety issue since these lesions could be utilized as a bacterial entry point. As a result, the carcass quality suffers [28].

\section{Viruses and Infectious Diseases}

\section{Pathogens}

Reovirus, Mycoplasma sinoviae, Staphylococcus aureus, and Retroviruses are the most common infections that cause lameness.

\section{Reovirus}

Avian reoviruses, which cause viral arthritis and tenosynovitis (tendon sheath inflammation), are common in the broiler business. The virus is thought to propagate by 'avian egg transmission, especially because the infection was discovered in seemingly normal commercial chicken embryos. Mild to moderate lameness characterizes the clinical picture, with enlarged "hocks" and a significant increase in fluid in the "hock" joints [29].

\section{Mycoplasma Synovial}

Mycoplasma Synoviae causes respiratory infections in hens and turkeys, as well as airsacculitis and synovitis. M. synoviae's effects were originally discovered in the 1950s, and the organism is still known. The pathogenicity of distinct strains of M. synoviae is a distinguishing feature of the organism. The disorders of the respiratory tract and/or synovitis appear to be unaffected by any of these [30].

\section{Retroviruses}

The avian leucosis viruses are among the most significant retroviruses. They are further split into subcategories. One of the most economically important diseases in broilers is avian leucosis virus subgroup J (ALV-J). The nodes are made up of myelocytes with eosinophilic cytoplasmic granules. Other forms of lesions, such as lengthy sarcomas with aberrant feathers and myelocyte infiltration in the bones and periosteum of the sternum and ribs, may develop [31].

\section{Staphylococcus Aureus}

In the commercial Poultry, Staphylococcus aureus is a major source of disease. S. aureus infection can result in septicemia (the prevention of harmful bacteria and their toxins in the blood), bone and joint infections, abscesses, and dermatitis, among other clinical manifestations [32]. Such diseases affect animal welfare and result in financial losses at the slaughterhouse owing to downtime, lower production, and corpse contamination [33].

\section{Mycotoxins}

Mycotoxins are one of the dietary variables that induce skeletal illnesses including Rickets, Articular Gout, and Tibia Dyschonroplasia, as well as a number of other bone diseases in broilers [34]. Because mycotoxins such as aflatoxin, ochratoxin, and fusarium toxin are poisonous to the liver and kidney, they cause rickets by preventing vitamin D3 conversion and absorption [35].

\section{Lameness}

Lameness is the leading cause of poor wellbeing in broiler hens, according to European Commission research [36]. Lameness is a broad term for a variety of broiler chicken injuries caused by infectious and non-infectious sources [37]. In the broiler business, lameness is also a major issue. The financial losses caused by lameness in commercially raised broilers are significant [38]. The cost of lameness in the United States was estimated to be between $\$ 80$ million and \$120 million in 2010 [39].

\section{Causes Lameness}

Infectious diseases, heredity, sex, weight and growth rate, age, feed conversion efficiency, nutrition, handling, and movement are all variables that contribute to lameness. These aspects will be explored in greater detail further down [40]. The genetic selection and management of non-infectious and non-nutritional bone abnormalities are the most important variables here [40].

\section{Weight and Growth Rate}

The quickly rising weight will place additional demands on the juvenile skeleton, and the resulting form change may affect the forces generated throughout the run. The high 'Gait Score' in broilers might be due to discomfort, biomechanical issues, or a combination of the two [41]. Observed at the connection between lameness, weight, growth rate, and age. Weight and growth rate were found to be significant variables in the development of lameness [42]. 


\section{Gender}

Lameness affects both males and females. Male chicks, on the other hand, have greater difficulties than female chicks, even when body weight is taken into account. The male had a 'gait score' that was nearly half a unit higher [43].

\section{Genetics}

There is evidence that the prevalence of 'leg weakness' differs between different commercial breeds that perform similarly in other areas [44]. Various genetic studies have revealed that the aetiology of lameness is bone anomalies with a degree of heredity [45]. Lameness appears to be more frequent in some breeds than in others. As a result, positive selection against these traits is feasible [46].

\section{Age}

It was discovered that with age, one's ability to walk correctly diminished [47]. The hens could still run well at four weeks of age. Less than $1 \%$ of these birds got a gait score of 4 or 5 . At 6 weeks of age, broilers walked substantially poorly and could run significantly worse. The pace at which the chicks deteriorated was faster between 4 and 6 weeks than between 6 and 7 weeks [47].

\section{Feed (Nutrients)}

Nutrients have been demonstrated to be crucial for proper skeletal development. To avoid leg problems in broilers, they need a well-balanced feed. A lack of water-soluble vitamins, manganese, or zinc, for example, might result in shorter bones with valgus anomalies. In addition, a shortage of nutrition in fast-growing hens might aggravate 'rickets' [48]. Biotin deficiencies in feeding regimens resulted with an increase in footpad dermatitis [49].

\section{Feeding Schedule and Composition}

The development of bone abnormalities that are not induced by infection can be reduced by reducing the growth rate by dietary restriction. It's possible that calorie restriction works by decreasing muscle tissue growth, allowing bone tissue to grow at a faster pace. A study was conducted to see if changing the feed pattern or the early feeding pattern would have an effect [50]. A reduced incidence of TD, less "hock burn, a better stride, lower body weight, and improved feed conversion were all linked to fewer meals per day. It was hypothesized that this was due to a well-organized eating schedule, which resulted in increased activity [49].

\section{Management}

Bedding, ventilation, heating, lighting schemes, feeding, occupation, and cage enrichment are only a few examples of management. Consultants, according to management, are deficient in these factors, which is the primary reason of the high prevalence of foot pad dermatitis. Producers are urged to enhance ventilation and begin reasonably early. It's also a good idea to use thin layers of litter and switch from straw to wood shavings every now and again. Scraping the hens would be easier, and it would be easier to keep it dry and ventilated [51].

\section{Litter}

Litter on the ground is crucial for keeping chickens. An excellent litter material is one that can absorb and release a significant amount of moisture. Wine wood shavings and straw are the most often utilized materials in practice [52]. It was also shown that chicks that sat on wood shavings were more active than those which were on straw. This might also be an opportunity to be less lame [53].

\section{Heating and Ventilation}

Leg problems are more common when the weather is either hot or too cold. When there is a low occupancy, it is clear that the air has minimal impact on the quality of the chicks. The environment has an effect at a greater occupancy. The proportion of chicks with sick feet is smaller, and they are less dirty [54].

\section{Lighting}

To enhance food intake and development rate, the broiler industry uses a continuous lighting or almost continuous illumination (23 h light: $1 \mathrm{~h}$ dark) standard [47]. Light may have a variety of effects on behavior, physiology, and well-being. Different light times have been observed to impact the lameness and development of chicks in research [5].

\section{Density (Placement)}

High occupancy may be used in a variety of ways to gain the most economic benefit. However, the capacity of the surface is restricted due to the negative impacts on development and quality. The chicks' exterior quality is clearly influenced by their employment. The quantity of chicks with red heels is substantially smaller and the redness of the soles is notably less at the lower occupancy of 16 chicks per m2. Furthermore, with low stocking densities, there are fewer variations for less dirty chicks [5].

\section{Enrichment}

From 33 days, it was proven that birds that were taught had less bone defects [3]. The sober environment may aid in the movement of the young ladies. Various initiatives to improve the surrounding environment have been attempted. Enriching the broiler house can increase activity and enhance the health of hens' bones, as well as their wellbeing [55].

\section{Assessment of Lameness}

Manual grading of bird movement and other farm activities are among the traditional ways for determining the gait score as a lameness indicator. Nonetheless, scoring the actions of broiler 
chicks is challenging. Fully automated image analysis approaches have numerous potentials for lameness assessment as compared to older methods. Because it is becoming cheaper, an automatic video image approach to assess activity as an indication of lameness in broilers is becoming more common [51]. It is also a noncontact technique, allowing for more frequent data collection during the lives of broiler chicks. When data is automatically analyzed in realtime, there is no need for large data storage [20]. Non-invasive and non-intrusive measures can also be taken constantly and automatically throughout the life cycle of birds. It also avoids the biosecurity risk of having individuals visit various commercial farms to conduct visual gait grading for boiler chicks [16].

\section{Manual Assessment (Gait Scoring System)}

The first manual evaluation approach for evaluating the gait issue in birds by visually examining and assigning gait scores to each broiler chicken [56]. This technique assigns a score ranging from zero (no leg issues) to five (totally paralyzed) based on the following factors. 0 (healthy broiler); 1 (broiler moves quickly but has a slight walking deficiency); 2 (broiler moves quickly but has a significant walking deficiency); 3 (broiler moves quickly but has a significant deficiency); 4 (broiler cannot move quickly and has a serious difficulty); and 5 (broiler cannot move quickly and has a serious difficulty) (the broiler cannot move anymore).

\section{Bristol's System of Scoring}

The Gait Scoring Guide from the University of Bristol is frequently used to measure walking ability. The idea behind this rating system is the same as the Gait Scoring System. Each broiler is given a score from 0 to 5 based on a set of criteria. Experts determine the score [57]. Although this approach is popular due to its simplicity, it is still very subjective. It is dependent on the observer's knowledge and experience. Other research has found that the visual gait score's repeatability isn't fully dependable. According to other research, just the movement, not the pressure produced by the chick, is measured with this approach. As a result, it will not provide objective information on whether or not the animal is in pain [58].

\section{Automated Assessment Systems}

\section{System of Pedobarographs}

The intensity of the light will be proportional to the amount of pressure exerted [4]. A custom-built pedobarograph was used to do the gait analysis. The emulsion side of the photographic paper pressed closer against the glass when pressure was applied to the surface, distributing the light. On the bottom of the glass, you can see this. In order to protect the birds, the glass plate and the career were both covered with polythene-backed protective sheeting" (Benckhote, Whatman International Ltd). A 45-degree angle mirror is used under the glass to provide a uniform surface. The mirror reflects the split light, which is recorded using a closed circuit camera (Panasonic WV-BP3101B0). Images were uploaded to a Powermac 8100/110 computer with a Scion LG-3 frame grabber card and processed using Scion Image (version 1.57) software after the video was captured on an S-VHS recorder (Panasonic AG-7355) (Scion Corporation, Maryland, USA). There were 12 frames per second in this experiment. Depending on the brightness of the point, each pixel is assigned a value between 1 and 254 . After that, the system may be calibrated to correspond to applied pressure [59]. The following gait characteristics were assessed and compared between the groups:

1. Acceleration $(\mathrm{m} / \mathrm{sec})$

2. Step rate (steps per minute)

3. Depth of the step

4. The length of each step

5. The angle of the step

\section{Video Recordings}

The behavior of broiler chickens examined in relation to lameness in another research [26]. Between the ages of 39 and 49 days, comparisons were made between healthy broilers and lame birds. Healthy birds slept $76 \%$ of the time and stood and/or moved $24 \%$ of the time. Broilers with a gait score of 3 spend $86 \%$ of their time laying down. Broiler age was similarly linked to an increase in lying occurrences [39].

\section{Latency to a Lie Detector Test}

Another approach for determining lameness in broilers was reported by [4]. The length of time that birds stood in water was assessed, and the results were compared to previous findings. There was a significant $(\mathrm{P}<0.001)$ connection between bird gait ratings and LTL. In a broiler house, over 750 chickens between the ages of 32 and 45 days were examined. Almost all of the healthy broilers could stand for at least 15 minutes, whereas the majority of the lame broilers were able to sit down in less than five minutes.

\section{Avian Gate Force Plate Research}

Another method was developed by (Thapa et al. [58] to define the ground reaction force of birds. While the broilers walked on the experiment setting, the ground reaction force was measured. GRF patterns showed significant growth shifts. The force plate was shown to be an acceptable study instrument for capturing broiler ground response force patterns.

\section{Broiler Lameness May Be Detected Using Precision Livestock Husbandry Techniques}

Automatically monitoring broiler chicken activity is one of the simplest techniques to detect lameness in broiler homes. Created 
a completely automated monitoring system to track the activity of broilers at various gait scores [26]. An automated video recording system was used to record the activity. The created system then automatically evaluated the pictures of the birds with six various levels of lameness. The findings revealed that there was a strong link between the lameness determined by an expert and the activities captured by an image monitoring technology [26]. There was also a significant decrease in the activity of broilers with a high gait score (GS4\&GS5). As a result, it was determined that this approach may be utilized in broiler houses as an indication of high lameness levels (GS4\&GS5). Another study [31] used image analysis to establish a novel approach for estimating the geographical usage of broilers. The lameness and the mobility captured by the image monitoring technology had a significant connection in both tests. The findings also revealed that there was a substantial correlation between broiler spatial usage and lameness degree and activity. As a result, it was also determined that the spatial usage of broilers may be used as a sort of activity indicator and criteria for determining lameness $[4,60,61]$.

\section{Conclusion}

Leg weakness encompasses a wide spectrum of anomalies related to a variety of etiological reasons, as detailed in this research. It is clearly impacting the development and end-weight of broiler chickens, resulting in a significant financial loss for the farmer. As previously stated, many distinct factors impact broiler chicken leg weakness, which must be taken into account while handling broilers. Leg weakness can be avoided by altering the surroundings and eating habits. Artificial lighting and restricted nutrition can also slow down development rates. However, effective mental management techniques should be used.

\section{Conflict of Interest}

There is no conflict of interest.

\section{References}

1. Baere De, Zoons KJ (2003) Strooiselkwaliteit bij vleeskuikens: een belangrijk aandachtspunt. Pluimvee Nr: 36.

2. Akbas YS, Yalcin S, Özkan, Kırkpınar F, Takma Ç et al. (2009) Heritability estimates of tibial dyschondroplasia, valgus-varus, foot-pad dermatitis and hock burn in broiler. Arch Geflügelk 73(1): 1-6.

3. Aydin A, Cangar O, Eren Ozcan S, Bahr C, Berckmans D (2010) Application of a fully automatic analysis tool to assess the activity of broiler chickens with different gait scores. Computers and Electronics in Agriculture 73(2): 795-802.

4. Aydin, Bahr AC, Berckmans D (2015) Automatic classification of measures of lying to assess the lameness of broilers. Animal Welfare 24(3): 335-343.

5. Aydin, Bahr AC, Pluk A, Leroy T, Berckmans D (2013) Automatic identification of activity and spatial use of broiler chickens with different gait scores. Transactions of the Asabe 56:1123-1132.
6. Baere De, Zoons KJ (2004) Welzijn bij vleeskuikens. Pluimvee Nr: 37

7. Grandin T (2007) Poultry slaughter plant and farm audit: critical control points for bird welfare. Information.

8. Bessei W (2006) Welfare of broilers: A review. Worlds Poultry Sci J 62(3): 455-466.

9. Corr SA, Gentle MJ, Mccorquodale CC, Bennett D (2003) The effect of morphology on walking ability in the modern broiler: a gait analysis study. Animal Welfare 12(2): 159-171.

10. Corr SA, Mccorquodale CC, Gentle MJ, Bennett D (2007) Evaluation of Ground Reaction Forces Produced by Chickens Walking on a Force Plate. American Journal of Veterinary Research 64(1): 76-82.

11. Dhillon AS, Thacker HL, Dietzel AV, Winterfield RW (1981) Respiratory cryptosporidiosis in broiler chickens. Avian Diseases 25(3): 747-751.

12. Cook ME (2000) Skeletal deformities and their causes: Introduction. Poultry Sci 79(7): 982-984.

13. Hussain A, Bilal M, Habib F, Gola BA, Muhammad P, et al. (2019) Effects of low temperature upon hatchability and chick quality of Ross-308 broiler breeder eggs during transportation. Online J Anim Feed Res 9(2): 59-67.

14. Ekstrand C, Carpenter TE, Andersson I, Algers B (1998) Prevalence and control of foot-pad dermatitis in broilers in Sweden. British Poultry Science 39(3): 318-324

15. Dawkins MS, Lee HJ, Waitt CD, Roberts SJ (2009) Optical flow patterns in broiler chicken flocks as automated measures of behavior and gait. Appl Animal Behav Sci 119(3-4): 203-209.

16. Hussain A, Yousaf A, Mushtaq A (2018) Prevalence of mycoplasma gallisepticum in ross-308 broiler breeder through the contrast of serological assessments in Pakistan. J Dairy Vet Anim Res 7(1): 00185.

17. Jabbar A, Hameed A, Yousaf A, Riaz A, Ditta YA (2019). The Influence of Hairline Crack Eggs on Hatchery Parameters and Chicks Performance. World Vet J 9(2): 76-83.

18. Corr SA, Mccorquodale CC, Gentle MJ (1998) Gait Analysis of Poultry. Research in Veterinary Science 65(3): 233-238.

19. Corr SA, Mccorquodale CC, Gentle MJ, Bennett D (2003) The effect of morphology on walking ability in the modern broiler: A gait analysis study. Animal Welfare 12(2): 159-171.

20. Dawkins MS, Cain R, Roberts SJ (2012) Optical flow, flock behavior and chicken welfare. Animal Behavior 84(1): 219-223.

21. Haslam SM, Brown SN, Wilkıns LJ, Kestın SC, Warrıss PD (2006) Preliminary study to examine the utility of using foot burn or hock burn to assess aspects of housing conditions for broiler chicken. British Poultry Science 47(1): 13-18.

22. Bradshaw RH, Kırkden RD, Broom DM (2002) A review of the aetiology and pathology of leg weakness in broilers in relation to welfare. Avian and Poultry Biology Reviews 13(2): 45-103.

23. Jabbar A, Yousaf A, Hameed A, Riaz A, Ditta YA (2019) Influence of Fumigation strength on Hatchery Parameters and Later Life of Chicks. J Holistic vet Sci Ani Care 1(1): 101.

24. Cordeiro AFS, Nääs IA, Salgado DD (2009) Field evaluation of broiler gait score using different sampling methods. Braz J Poultry Sci 11(3): 149154.

25. Jabbar A, Yousaf A (2017) Effect of age wise incubation programme on broiler breeder hatchability and post hatch performance. Online J Anim Feed Res 7(1): 13- 17

26. Rushen, Chapinal JN, Passille AM (2012) Automated monitoring of behavioral-based animal welfare indicators. Animal Welfare 21: 339350 . 
27. Julian RJ (1998) Growth problems: ascites and skeletal deformities in broilers. Poultry Science 77(12): 1773-1780.

28. Sanotra GS, Lund JD, Ersboll AK, Petersen JS, Vestergaard KS (2001) Monitoring leg problems in broilers: a survey of commercial broiler production in Denmark. Worlds Poultry Science Journal 57(1): 55-69.

29. Kestin SC, Gordon S, Su G, Sorensen P (2001) Relationships in broiler chickens between lameness, liveweight, growth rate and age. Veterinary Record 148(7): 195-197.

30. Kestin SC, Knowles TG, Tinch AE, Gregory NG (1992) Prevalence of leg weakness in broiler chickens and its relationship with genotype. Vet Record 131(9): 190-194

31. Kjaer JB, Su G, Nielsen BL, Sorensen P (2006) Foot pad dermatitis and hock burn in broiler chickens and degree of inheritance. Poultry Science 85(8): 1342-1348.

32. Su G, Sørensen P, Kestin SC (1999) Meal feeding is more effective than early feed restriction at reducing the prevalence of leg weakness in broiler chickens. Poultry Science 78(7): 949-955.

33. Scahaw (2000) The welfare of chickens kept for meat production, Report of the Scientific Committee on Animal Health and Animal Welfare Brussels, Belgium, European Commission, Health and Consumer Protection Directorate-General.

34. Khan A, Rind R, Shoaib M, Kamboh AA, Mughal GA, et al. (2016) Isolation, identification and antibiogram of Escherichia coli from table eggs. Anim Health Prod 4(1): 1-5.

35. Su G, Sørensen P, Kestin SC (2000) A note on the effects of perches and litter substrate on leg weakness in broiler chickens. Poultry Science 79(9): 1259-1263.

36. Sorensen P, Su G, Kestin SC (2000) Effects of age and stocking density on leg weakness in broiler chickens. Poultry Science 79(6): 864-870.

37. Weeks CA, Kestin SC (1997) Effect of leg weakness on the behaviour of broilers. Proceedings of the $5^{\text {th }}$ Poultry Welfare Symposium, Wageningen. The Netherlands, pp. 117.

38. Weeks CA, Danburry TD, Davies HC, Hunt P, Kestin SC (2000) The behaviour of broiler chickens and its modifications by lameness. Applied Animal Behaviour Science 67(1-2): 111-125.

39. Mathan, Jabbar A, Shahnawaz R, Yousaf A, Ahmad F, et al. (2020) Prevalence of Various Poultry Diseases in Different Seasons in District Rawalpindi, Pakistan". EC Veterinary Science 5(9): 87-92.

40. Kristensen HH, Aerts JM, Leroy T, Wathes CM, Berckmans D (2006) Modelling the dynamic activity of broiler chickens in response to stepwise changes in light intensity. Appl Animal Behav Sci 101(1-2): 125-143.

41. Knowles TG, Kestin SC, Haslam SM, Brown SM (2008) Green Leg disorders in broiler chickens: Prevalence, risk factors and prevention.

42. Mccullagh JJ, Mcnamee PT, Smyth JA, Ball HJ (1998) The use of pulsed field gel electrophoresis to investigate the epidemiology of staphylococcus aureus infection in commercial broiler flocks. Vet Microbiol 63(2-4): 275-281.

43. Lockaby SB, Hoerr FJ, Lauerman LH, Kleven SH (1998) Pathogenicity of mycoplasma synoviae in broiler chickens. Veterinary Pathology 35(3): 178-190.

44. Weeks CA, Knowles TG, Gordon RG, Kerr AE, Peyton ST (2002) New Method for Objectively Assessing Lameness in Broiler Chickens. Veterinary Record 151(25): 762-764.
45. Yousaf A, Jabbar A, Rajput N, Memon A, Shahnawaz R, et al. (2019) Effect of Environmental Heat Stress on Performance and Carcass Yield of Broiler Chicks. World Vet J 9(1): 26-30.

46. Yousaf A, Jabbar A, Ditta YA (2017) Effect of pre-warming on broiler breeder eggs hatchability and post-hatch performance. J Anim Health Prod 5(1): 1-4.

47. Yousaf A, Jabbar A, Laghari IH, Abbas M (2017) Effect of incubation duration on broiler breeder eggs hatchability and post-hatch performance. J Anim Health Prod 5(4): 127-131.

48. Yousaf A, Rajput N, Memon A, Naz Jagirani G, Shahnawaz R, et al. (2019) Effect of hatch window upon intestinal development, chick quality, post hatch performance according to Ross-308 broiler breeder age. Online J Anim Feed Res 9(1): 26-32.

49. Yousaf A, Rubab F, Shahnawaz R, Jamil T, Iqbal T, et al. (2016) Impact of semen quality of Aseel chicken on induced molting. Online J Anim Feed Res 6(6): 130-132.

50. Verma SD (2006) Mycotoxins affect bone structure and leg weakness. World Poultry, p. 11.

51. Yousaf A, Shahnawaz R, Jamil T, Mushtaq A (2018) Prevalence of coccidiosis in different broiler poultry farms in Potohar region (distract Rawalpindi) of Punjab- Pakistan. J Dairy Vet Anim Res 7(3): 87-90.

52. Vestergaard KS, Sanotra GS (1999) Relationships between leg disorders and changes in the behaviour of broiler chickens. Vet Record 144(8): 205-209.

53. Webster AJE (1995) A cool eye towards eden. Oxford, Blackwell Science, USA.

54. Rousing TM, Bonde, Sorensen JT (2000) Indicators for the assessment of animal welfare in a dairy cattle herd with a cubicle housing system. In Improving Health and Welfare in Animal Production, p. 37-44.

55. Yousaf A (2016) Impact of gender determination through vent sexing on Cobb-500 broiler performance and carcass yield. Online J Anim Feed Res 6(6): 125-129.

56. Yousaf A, Tabasam MS, Memon A, Rajput N, Shahnawaz R, et al. (2019) Prevalence of ascaridia galli in different broiler poultry farms of potohar region of rawalpindi-pakistan. J Dairy Vet Anim Res 8(1): 71-73.

57. Sullivan TW (1994) Skeletal problems in poultry: Estimated annual cost and descriptions. Poultry Sci 73(6): 879-882.

58. Thapa BR (2004) Detection of avian leukosis virus subgroup j in chicken flocks from Malaysia and their molecular characterization. Avian Pathol 33(3): 359-363.

59. Cangar, Cardinaels OS, Everaert N, Keteleare B De, Bahr C (2009) A study on the cause and effect of lameness on broiler chickens. In Proc Joint Int Agric Conf: Precision Livestock Farming.

60. Garner JP, Falcone C, Wakenell P, Martın M, Mench JA (2002) Reliability and validity of a modified gait scoring system and its use in assessing tibia dyschondroplasia in broilers. British Poultry Science 43(3): 355363.

61. Kristensen HH, Perry GC, Prescott NB, Ladewig J, Ersboll AK (2006) Leg health and performance of broiler chickens reared in different light environments. British Poultry Science 47(3): 257-263. 
ISSN: 2574-1241

DOI: 10.26717/BJSTR.2021.40.006433

Adnan Yousaf. Biomed J Sci \& Tech Res

(C) (P) This work is licensed under Creative

Submission Link: https://biomedres.us/submit-manuscript.php

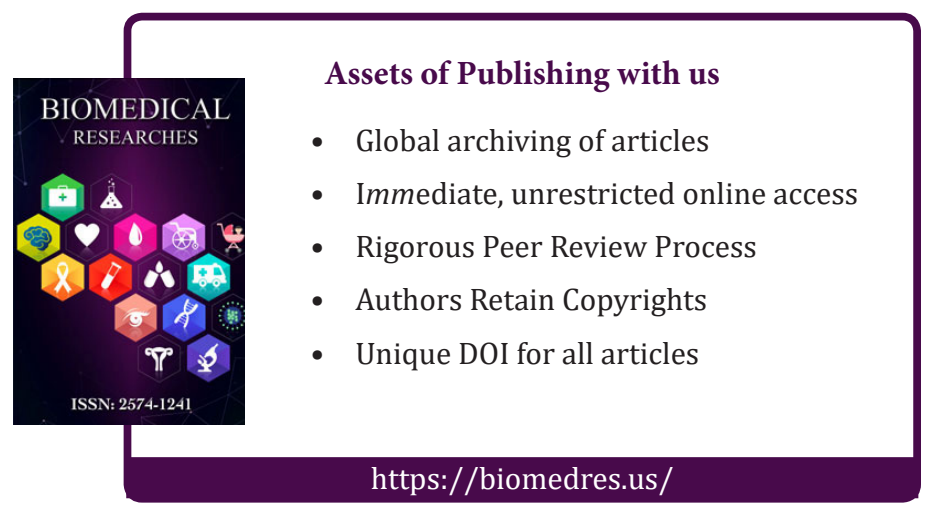

